\title{
VV. AA. alba Magazin lateinamerika lesen 10
}

Berlín, 2017, 99 páginas. ISSN: 2196-2375

La revista bilingüe ilustrada alba se caracteriza por publicar y traducir al alemán a emergentes autores latinoamericanos. Para ello cuenta con un equipo de académicos, intelectuales de las letras y traductores que se encarga de esta labor; en este número en particular colaboraron en la redacción, Sarah van der Heusen, Jorge Locane, Ingrid Hapke, Diana Grothues, Edna Martínez, Douglas Valeriano Pompeu, Thomas Schlegel, María Ignacia Schulz, Karina Theurer y Christianne Quandt; y en las traducciones, Susanne Lange, Simone Reinhard, Carsten Regling, Johanna Schwering, Rike Bolte, Claudia Sierich, Aron Zynga, Léonce W. Lupette; esta última labor compartida en muchos casos con los primeros. Con su ayuda, todas las contribuciones escritas en español o portugués que aparecen en sus páginas, son íntegramente traducidas al alemán.

alba antologa y publica poesía, cuento, entrevistas, reportajes/notas y críticas literarias sobre escritores de América Latina -estas últimas solo en alemán, porque se trata de críticas de obras recientemente publicadas en el mercado germano, para ser más concretos, las que aparecen en el número que ahora reseñamos corresponden al año 2016: como la obra del colombiano Tomás González Was das Meer ihnen vorschlug (Primero estaba el mar, 1983), de la argentina Selva Almada, Sengender Wind (El viento que arrasa, 2012) y del mexicano Juan Pablo Villalobos, Ich verkauf dir einen Hund (Te vendo un perro, 2015).

Por una parte, alba recoge contribuciones que han aparecido en antologías o ediciones, ya se trate de cuentos, textos, fragmentos de novelas, entre otros. Por otra parte, se organiza de acuerdo a secciones temáticas -las que no siempre aparecen en todos sus números-: "Vanguardias”, "Voces perdidas”, "Entrevista”, "Panorama”, “Mediaciones”, “Transferencias”,

“Traducción”, "Reseñas”, además de la que se encuentra al comienzo de la revista: Berlínstant y/o Latínstant. Se trata de dos miradas breves: de un latinoamericano a Berlín (Berlínstant) o de un germanófono a América Latina (Latínstant). De esta forma, incorpora entrevistas y reportajes inéditos, los que adquieren notoria divulgación gracias a su inclusión en la revista. Entre estos últimos, y para este volumen se encuentra el reportaje sobre el escritor peruano Reinaldo Jiménez escrito por Léonce W. Lupette. El texto está acompañado por una selección de sus poemas extraídos de la obra La curva del eco (2008) y un fragmento de la entrevista al autor brasileño Luiz Ruffato realizada por Douglas Valeriano Pompeu y Thales Barreto de Castro.

alba representa así, un esfuerzo por proyectar interludios entre Latinoamérica y Alemania, entendidos como intercambios e interpretaciones intercontinentales y reflexiones 
sobre el concierto literario latinoamericano. Cabe destacar que Berlín es el escenario de una rica "escena” artística y cultural protagonizada por latinoamericanos y desarollada bajo los efectos de Latinale mobiles lateinamerikanische poesiefestival del cual alba ha resultado ser uno de sus grandes actores y principales difusores.

Desde los inicios de la revista, cerca de marzo de 2012, esta ha ostentado un carácter libre a la hora de armar sus números, aunque ha dedicado ediciones especiales a una temática o un aspecto en particular en algunas entregas, ya sea a través del foco puesto en un país como lo hicieran en su momento con Chile, Brasil y ahora México- un tópico u otros intereses. Ya lo dicen los editores en el número inaugural de la revista:

“alba” es producto de un trabajo entusiasta y desinteresado. Con sus páginas de aparición semestral [anual desde el 2016] sólo queremos participar del sueño de voltear hasta el último muro para tratar de encontrarnos en el coro de las diferencias. Por eso, “alba” también es una utopía. Una pretensión. Una apuesta por escrituras y pensamientos pluriversales” (2012, s.p.).

En su actual número 10, alba parece honrar esa premisa elaborada desde el comienzo y recuerda en la "Editorial” la celebración del año dual de México y Alemania con la publicación de prosa, poesía, ensayos, entrevistas y reseñas de literatura latinoamericana, que en la mayoría de los casos rinde tributo a este lazo intercontinental.

La "Editorial” $\mathrm{N}^{\circ} 10$, traducida al español por uno de los principales colaboradores y cofundador de la revista, Jorge Locane, parte con una cita de Jacques Derrida ("cierta poética es la única que puede desviar una interpretación dominante”) que pretende evitar las interpretaciones absolutas, en este caso, en la creación literaria. Los editores señalan así: "apostamos por el poder de cambio de perspectiva, por la irritación estimulante de los acontecimientos ocultos, por el acto de leer como acto de repliegue interior” (2017, p. 3). Este número está abocado a descentrar los énfasis teóricos del telurismo interpretativo y cierra su columna de presentación con las palabras de uno de sus antologados, el mexicano Yuri Herrera quien dice: "La literatura no explica ni ratifica ni ofrece respuestas simples, por el contrario, quiere provocar la duda a partir de un acontecimiento estético” (2017, p. 3). El escritor mexicano reaparece en las primeras páginas de la revista con Der Akt des Schweigens/ El acto del silencio; una versión abreviada de su discurso de aceptación del Premio Anna Seghers que le fuera entregado en Berlín el 18 de noviembre de 2016.

Tras esta declaración de principios de alba, la nueva entrega sigue con las contribuciones de poetas y narradores mexicanos como Rocío Cerón (breve selección del poemario Borealis, 2016); Ana García Bergua (el relato “Despertar” de su libro La tormenta hindú, 2015); Maricela Guerrero (los poemas bajo el título "Erosión” tomados de Fricciones, 2016); Paula Abramo (“Moscas” de la antología Siete rutas hacia el bosque alemán, 2016); Ignacio Padilla ("Las furias de Menlo Park" de su obra El androide y las quimeras, 2008), y Xitlalitl Rodríguez 
Mendoza ("Apnea del sueño" de la antología Transfronterizas: 38 poetas latinoamericanas, 2016) a los que se suman prominentes selecciones de poemas de los escritores venezolanos Rafael Cadenas y Yolanda Pantin, además de un fragmento de la novela El sonido de la $H$ (2015) de la boliviana Magela Baudoin.

En su conjunto, los autores comparten ciertas inquietudes que actúan como conductores de las mismas premisas sostenidas en las palabras anteriores.

La revista despunta (al alba) en la entrega de varias poéticas reveladas; coordenadas dialogantes entre ambos países que anuncian voces erotizantes, estimulantes, de ecos históricos alucinantes/ados. Las voces y los personajes deambulan y hablan de diásporas y encuentros de amantes de la fijación, fetiches de lo objetual/animal -como en el relato "Cosita"- quebraduras del pensamiento (muerto), definiciones reconvenidas sobre sí mismas como en "Inaudito picnic berlinés" de Villalobos; "Moscas" de Abramo o "Despertar" de García Bergua.

Como elemento central, surge una suerte de homenaje a la escritora alemana Anna Seghers, quien aparece con el fragmento de Die Gemalte Zeit/ El tiempo pintado, texto originalmente titulado Die Gemalte Zeit. Mexikanische Fresken, incluido en su momento en Über Kunst und Wirklichkeit: II Erlebnis und Gestaltung (1971) de la misma Seghers junto a Sigrid Bock. En esta crónica Seghers recuerda la penetrante impresión que le dejaron los murales mexicanos y la trascendencia del mensaje atrapado en su colorido.

Visualmente, la revista es un deleite de principio a fin. Invita al lector a embarcarse en el cruce entre continentes recurriendo a talentosos ilustradores, como Raúl Ballesteros, Vincent Díaz Negrón, Fede Tauss, Omar Alonso, Andrés Barthel Agostino, Tuto Castillo, Diego Castillo y Daniel Hache, quienes no siempre juegan a traducir en forma "literal" las palabras al ámbito de la visualidad, sino que colocan el énfasis en la ironía, la ternura e incluso la sorpresa, como en la imagen de entrada que da forma a la portada, la que comparte el espacio con un breve poema intitulado del colombiano Rodolfo Lara Mendoza, inspirado en la obra Espíritus y Sal del artista visual mexicano Víctor Esquivel, imagen que nos señala el derrotero del mismo: el vuelco de alba hacia el germen literario del país azteca. Es necesario mencionar que alba 10 es la primera edición que dedica una página a la presentación de los artistas visuales que en ella colaborar.

Otro ejemplo preclaro de la atractiva conjunción verbo-visual de alba es el homenaje “in memoriam Luis Alberto Arellano (1976-2016)”, autor mexicano recientemente fallecido, que consiste en una fotografía del autor acompañado por un breve texto suyo que dice:

Porque no hay remedio/ porque nos tomaron por asalto y ahora colgamos de puentes colgantes/ porque la certeza es mayor que el miedo [...]/ porque nunca tuve nada/ porque nunca tendré todo/ porque afuera hace frío/ porque no hay nombres para los objetos que hemos perdido [...] fragmentos del poema "Tiro de gracia” de Bonzo del 2012 (2017, p. 29).

Pese a que desde el inicio se advierte el respiro de una contribución dialógica y equitativa de las contrapartes idiomáticas, predomina el alemán por sobre el español, por cuanto los 
títulos en ese idioma duplican por lo menos, el tamaño de la fuente de las letras en español (o en portugués). Pero este desequilibrio, pasa desapercibido cuando se observa una armonía, tal vez intencional, en la incorporación de contribuciones de hombres y mujeres. Un buen ejemplo es el último texto de la revista, una entrevista a Guadalupe Nettel "Por una literatura (mexicana) con conciencia”, es una muestra singular de la literatura fuera del género, pero comprometida consigo misma o situada en el entrecruce. La autora mexicana apuesta por una literatura que evada la enfermedad (ceguera), que evada el bullying.

alba es una publicación necesaria en el concierto de la difusión y el reconocimiento de la literatura latinoamericana, y en español y en portugués como en alemán; tanto para su propia circulación en Alemania, primordialmente, como en América Latina. Ha sabido poner en tensión, a través de su continuo y arduo trabajo de traducción y publicación, valores casi naturalizados en torno a la literatura en general que suelen persuadir a la academia de guiarse por los cánones establecidos que defiende con ímpetu. También huye, y se admirara como un acierto, de las modas de las grandes casas editoriales y del arrastre e impulso que alimenta últimamente a muchas revistas que esperan entrar al cerrado círculo de la indización a través de artículos plagados de sesudos análisis.

La revista no se resta a esto último, por cierto, pero ofrece un espacio dialéctico, franco y abierto a que las contribuciones reseñadas, a los cuentos, presentados a través de entrevistas a los escritores, acompañadas por la apuesta visual y rodeados por un cuidado diseño interior y exterior, que invita al lector a realizar una lectura de acuerdo a sus coordenadas e intereses. No deja de ser una inmersión en la que este se sume sabiendo que se encuentra ante reflexiones profundas, cuidadosamente entregadas para su lectura y revisión. Precisamente el artículo "El estridentismo mexicano. Una vanguardia radical radial" escrito por Christiane Quandt, introduce el componente intermedial que la radio aporta a este movimiento literario en el país azteca, precisamente en el año 1921, fecha que se apunta en el epígrafe de Los detectives salvajes de Roberto Bolaño ubicado al comienzo del texto: " $y$ mientras bebía les iba leyendo trozos de aquel lejano año de 1921 y lo íbamos comentando, los párrafos y el mezcal (2017, p. 16). La autora destaca la importancia del sonido, sobre todo del transmitido por la nueva tecnología radial a través de la cita de poemas como "T.S.H" de Manuel Maples Arce y RADIO. Poema inalámbrico en trece mensajes de Luis Quintanilla del Valle (Kyn Taniya).

Las ilustraciones y fotografías tocan diferentes teclas: unas más poéticas y metafóricas, otras netamente referenciales y de registro, otras lúdicas y enternecedoras. Todas, sin embargo, cumplen su cometido, dependiendo del momento en que emergen en las páginas.

La oferta bilingüe de alba no es un freno a la hora de enfrentar la lectura, por el contrario, los editores han sabido distribuir magistralmente el material en sus páginas de forma de que la lectura sea agradable y orgánica. Lo mismo aplica para las contribuciones en portugués.

Un punto en contra talvez seríano contar con traducciones al español delas contribuciones del portugués que solo se traducen al alemán, como la entrevista a Ruffato o la pieza escrita por Douglas Valeriano, titulada "Eine Bresche im Deutschen Leserbewusstsein”/“Uma brecha 
na consciência do leitor alemão". Tal vez se explica por lo complejo de poner en las planas una versión trilingüe de los mismos; tal vez podría ofrecerse esta versión en una puesta digital de la revista; podría constituirse en una excelente plataforma para exponer en la Web in extenso las contribuciones que en la versión en papel aparecen abreviadas. También podría ser esto útil, cuando se trata de las reseñas críticas ubicadas en las páginas finales de la revista. Insisto en que puede tratarse de la misma causa, en tanto alba persigue que América Latina/Hispanoamérica/Iberoamérica se lea y reflexione en el compartir de sus intelectuales, pues estos contribuyen a nombrarnos como complejo cultural integrado, aunque se trate de una posibilidad compleja e idealizada, debido a fricciones y tensiones siempre presentes e incluso necesarias. Insiste en el reconocimiento del conglomerado brasileño, como una fuente reconocible, fructífera y productiva de acervo cultural que se expande al resto del continente.

Frente al tributo al vínculo entre México y Alemania, el espacio ocupado por los artistas de otros países otorga a la revista un prolongado sentido continental o trasatlántico. Esta es una característica insigne de alba que se desliza desde la aparición de su primer volumen hasta el número actual, coronando 5 años y 10 ediciones de permanente relevamiento literario.

Dra. LoRena LÓpez TORRES

Universidad Católica del Maule

LPLOPEZ@UCM.CL 